\title{
THE LANGUAGE FEATURES OF MALE AND FEMALE BEAUTY INFLUENCERS IN YOUTUBE VIDEOS
}

\author{
Clara Herlina Karjo \\ Department of English Literature, Bina Nusantara University, Indonesia \\ E-mail: claraherlina@yahoo.com \\ Stephani Wijaya \\ Department of English Literature, Bina Nusantara University, Indonesia \\ E-mail: tephtastic@gmail.com
}

\begin{abstract}
APA Citation: Karjo, C. H., \& Wijaya, S. (2020). The language features of male and female beauty influencers in YouTube videos. English Review: Journal of English Education, 8(2), 203-210. doi: 10.25134/erjee.v8i2.2593.
\end{abstract}

\begin{abstract}
Nowadays, the beauty community has a rapid growth of beauty influencers from both genders. The language style that is used on each gender has its own features and characteristics that can be explored from video sharing platform, YouTube. The aim of this study is to find the language features and distinctive characteristics of the male and female beauty influencers and the differences of comments from their audience. The writer applies qualitative research method by using text analysis of the video script. The data shows that male and female beauty influencers have shown differences in their features and characteristic of language. Men beauty influencers tend to be more straightforward and directive. They also use a more plain and simple words. On the other hand, the women beauty influencers are more polite and intimate in using language. This study is hoped to be the foundation for further research in the same topic of language feature in gendered community within limited topic especially in this modern era.
\end{abstract}

Keywords: gender; language features; characteristics; beauty influencers; YouTube.

\section{INTRODUCTION}

The internet contains different kinds of contents that can be accessed such as personal blogs, education blogs, social media and many kinds of entertainment content. The entertainment aspect of internet can be found from the social media such as Instagram as a photo sharing platform or YouTube as a video sharing platform. YouTube in particular, has grown for the past decade containing a wide variety of contents. Among the most popular contents that can be found in YouTube are contents created by makeup and beauty community.

The beauty community content creators are popularly known as beauty influencers. They are usually endorsing and reviewing makeup brands or products for tutorial purposes. As make up products are usually targeted to women customers and the beauty community is exclusively linked to women, it is generally assumed that all beauty influencers are all women. In fact, in today's era, gender is no longer used as a limitation for one's occupation. Thus, there are males who also choose the profession as beauty influencers although the target viewers are still women.

Notwithstanding that any gender can choose gender stereotyped profession such as a beauty influencer, the language used by male and female still differ in some ways. This is because a person's language style is constructed due to the social structure in each person's environment such as how they have been raised in their family or what kind of neighborhood and school that the person attended (Eckert \& McConnel-Ginet, 2013). Moreover, male and female speaks differently in different social situation as it reflects the speaker's current roles, the topic, the context and the medium of communication and also the addressee (Gleason \& Ely, 2002).

Gender differences in communication are explained by the different roles that men and women hold in society (Lakoff, 2004). Lakoff (2004) maintained that women speech pattern differ from men because of their subordinate social status (Jan, 2017). In her seminal work, Lakoff (2004) suggested that women typically display a range of features such as specific terms of color, avoidance of harsh words, hedges, empty adjectives, tag questions, and intensifiers.

Previous studies mostly give greater attention to women's language features. On the contrary, men's language was rarely discussed in literature, except for the work of Coates (2016). Thus, the discussion of men's language characteristics was done by comparing them against women's language features. For example, if one feature of 
women's language is the avoidance of swear words, then in men's language the researcher is looking for the opposite, i.e. the use of swear words. The discussion of each language feature is detailed below.

The first feature relates to the use color terms. Women are known to be able to identify color terms as a different series and variation of shades with more detail and variation of the same shades whereas men's knowledge of color is limited to the primary colors as colors sometimes look very similar to each other. For example, women can differentiate between the lavender color and mauve; while man can just say purple. The precise and detailed manner of color identification by women is due to women's ability to differentiate accurate chrome and hue (PerezCarpinell, Baldovi, de Fez, and Castro, 1998). The women's ability to differentiate color precisely is due to the possibility of different standard of socialization between women and men that encourage women to have broader knowledge and awareness towards colors term and variation (Bimler, Kirkland, \& Jameson, 2004).

The second feature of women's language is the avoidance of harsh language. Women are generally expected to act like ladies, hence they are avoiding harsh language and instead implementing a polite and soft speech style in their language (Lakoff, 2004). When women have to use harsh language in their speech, they often replace it with euphemized form of harsh language such as what the heck to replace what the fuck. On the contrary, men were found to swear and use harsh language more often than women in their speech (Poynton, 1995).

The next prominent feature in women's language is the use of hedges. Hedges are used to soften the way people state their opinion, as they make statements to be less direct and less strong. Holmes (2013, p. 26) said that hedges may be one of the crucial aspect whether an expression is considered as polite or not from the perception of it. Hedges are commonly used in women's language to be used as a politeness device and the use of hedges can determine whether a statement can be labeled as polite or impolite from the way the speakers deliver their speech to their addressee. Mulac, Bradac and Gibbons (2001) stated that women use more hedges in their speech as compared to men. Crawford (2012) noted that women frequently use hedges because they choose to criticize others in more acceptable ways. They don't want to be seen as opposing others directly.

The next feature mentioned by Lakoff is the use of empty adjectives or women-only adjectives in women's speech. Lakoff (2004) suggested that women use adjectives as an act of appreciation and admiration towards something. Lakoff (2004) gave a collection of adjectives that are considered as women-only adjectives such as adorable, charming, sweet, lovely, and divine whereas neutral adjectives consist of words such as great, terrific, cool and neat. On the contrary, men mostly use judgmental adjectives in their speech as opposed to women who use adjectives as appreciation. Judgmental adjectives often used in particular to criticize others, as exemplified by Mulac, et al. (2001) in this sentence "His performance is poor". The adjective poor is indicated as judgmental adjective as it criticizes the person's performance.

The use of intensifier is also featured in women's language. Intensifier is a component that usually consists of adverb or adverbial phrase that acts as a modifier to give emphasis to the word behind it. The purpose of using intensifier is to strengthen the meaning of words. There are commonly used intensifiers such as so, really, very, absolutely, too, totally, extremely, etc. Lakoff (2004) found that the intensifier so is more prevalent in women's language rather than men's, even though there is no restriction for men to use it. Even though women use intensifier more frequently than men, men is found to use intensifier that is considered as negative intensifier instead of basic intensifier such as very and really to intensify the words that follow behind. Sardabi and Afghari (2015) explained that a particular intensification can be employed to the use of negative words to increase the effect of the positive context behind. In the example given by Sardabi and Afghari (2015), "She is dreadfully beautiful", the word dreadfully is considered as negative intensifier that intensifies the positive word behind it.

Besides the above features detailed by Lakoff, Tannen (2013) added several other features, namely rapport and report talk, being indirect, quoting others and extensive apposition. These features also differentiate male and female speech.

Rapport talk is defined by Tannen (2013) as the way when women establish emotional connection and relationships through their speech. Women use rapport talk to connect with their addressee. They prefer to talk in a more private manner as it will be felt as if the speaker is talking 
privately even if in a public situation. Talking in a private manner means the topic of the talk is heavily leaning to the feelings and past experiences and memories. This is done to create a relatable connection with the addressee. On the contrary, male speech is characterized by report talk. Instead of talking about private matters, men are found to talk about their knowledge and skill (Tannen, 2013). Men are also found to be more talkative during public speaking situation.

The next feature of women's speech is being indirect while stating their opinion especially when expressing dislike or unfavorable statement. Women often express something in a thoughtful and non-threatening manner towards other person especially while directing their opinions of dislike and disapproval. Crawford (2012) suggested that one of the main objectives of women is to criticize others in an acceptable and respectable ways, thus being indirect and ambiguous while doing so is applied and implemented in women's language in general. On the contrary, men love to state their opinion openly and in direct manner. As their objectives for speech is to assert their position and dominance, they tend to be more straightforward and more honest about what they think. Men are not afraid to state their opinion and criticize others; hence the directness will be shown in their speech.

Quoting someone else also appears in women's language. Lakoff (2004) claimed that women's personal identity is linguistically submerged by quoting what someone else has said. Quotation is a tool that uses the voices of others to convey their own opinion to avoid being direct in their speech. Finnegan (2011) explained that a quotation can be used as a tool to convey originality, to support or even oppose particular authority as well as approve and disapprove by using the voices of others. Crawford (2012) suggested that women often use quotation due to the fact that women are inferior in general where their position is submerged with the dominance of men. Hence, quoting other persons will give more credit and authority to their speech to make it more valid and authentic.

Finally, women are also known to use extensive apposition in their speech. Women generally adopt intensive and extensive form of word to their speech instead of plain and straightforward sentence. Women tend to use a lot of words especially when describing attributes towards someone (Lakoff, 2004). Mulac, et al. (2001) also suggested that women's language tend to have longer sentences and intensive words.

Different features of male and female speeches do not only occur in physical interaction but also in digital interaction, such as through social media. Several previous studies have confirmed that male and female showed distinctive language features in social media interaction. For example, in one study, Fatin (2015) found that men and women have different word choice in social media Twitter in which men's language was found to be harsher than women's. Women were observed to use weaker and more polite form of language. Another study by Broadbridge (2003) that examined the conversational style of men and women also discovered that women use more hedges while men use more vulgar term in their speech.

Moreover, Wahyuningsih (2018) found that women prefer to use women-only adjectives such as wonderful, extraordinary, etc. in their speech through the social media interaction.

The interaction that occurs in broadcasted platform such as YouTube use specific form and structure of language, which are termed as media discourse (Leitner, 2017). The interaction of media discourse involves the speakers or message senders and the addressees. However, the interaction in social media is referring more to the non-present addressee, reader, listener or viewer where they often cannot make immediate response towards the sender of the message (O'Keefee, 2013). Because of this non-present addressee, the interaction between the beauty influencers and their followers in YouTube platform is mostly dominated by the influencers themselves. The engagement and participation of the audiences is limited to giving comments and likes to the videos presented by the content creators.

Though the beauty influencers do not interact directly with their audiences, they still have to consider carefully the language they use in their videos. Thomson, Murachver and Green (2001) stated that language is not something that is fixed to individual but rather constructed to each conversation. That means, who the speaker is talking to also affect the type of language used by the speaker, no matter the gender of the speaker is. As the audiences of the beauty influencers' videos are mostly female, it is interesting to find out whether male content creators speak with their own language style or they accommodate their speech to that of their audiences.

Speech accomodation is defined by Giles \& Ogay (2007) as the constant movement toward 
and away from others by changing one's communicative behavior. Similarly, Holmes (2013b) defines speech accomodation as a process in which one person's speech converge towards the speech of the person they are talking to. Thus, using this equation, the beauty influencers' language in their videos will be converging towards their viewer's language. Yet, in their study, Thomson et al. (2001) found that both women and men converge to the language style more female or male like of their netpals. That means, women will converge to male style if their addresse is male; and vice versa.

The previous studies discussed above mostly deal language style of male and female speakers either in physical and digital interaction. However, almost none of the studies mention how the audiences or addresses affect the language styles of the speakers. Therefore, the present study, which probes the language style used by male and female beauty influencers on YouTube will be quite intriquing because they will be talking to female audiences. There are three research questions that will be explored in this study.

1. What distinctive language features do male and female beauty influencers show in their videos?

2. To what extent do male and female beauty influencers accommodate their speeches for their viewers?

3. What do the viewers comment about the beauty influencers?

\section{METHOD}

\section{Source of data}

The data for the present study were taken from four YouTube videos of four well-known beauty influencers, two female and two male. The first one is Nikkie, a Dutch beauty influencer who frequently uploaded beauty videos since 2008 . Nikkie has over 12 million subscribers on her channel. The second is Tati Westbrook, an
American beauty influencer who has become a beauty content creator since 2010 and has almost 10 million subscribers. The third one is Jeffree Star who has been in the industry since 2003 but he began uploading videos since 2013 and has 14 million subscribers. Lastly, Manny Gutierrez, a former beauty consultant who has opened his beauty channel since 2014 and has 5 million subscribers.

\section{Data collection procedure and analysis}

We selected one video from each beauty influencer, thus there are four videos used as the source of data. For the ease of analysis, all the videos cover similar topic, i.e. review of makeup foundation. The titles of the videos are:

1) Pores are shaking!! Fenty Beauty Concealer \& Setting Poweder Review by Nikkie.

2) Fenty Beauty Concealer \&Setting Powder ... Honest Non-Sponsored thought by Tati

3) The Truth.. Fenty Beauty Concealer \& Setting Poweder by Jeffree Star

4) Brutally honest Fenty concealer and powder review! By Manny Gutierrez

The videos were downloaded and transcribed. Besides the videos, 10 prominent viewers' comments of each video were also taken as the data. The analysis of the videos and the transcripts was done by identifying the speech features as detailed by Lakoff (2004) and Tannen (2013) in the speech of male and female beauty influencers. Meanwhile, the comments were also categorized as positive or negative feedback for the beauty influencers.

\section{RESULTS AND DISCUSSION}

The language that was used by four YouTube beauty influencers has its own distinctive characteristics and features that were shown in their videos. Thus each gender has differences in the characteristics of language that is shown in their speech although they were discussing the same topic.

Table 1. Men and women language features

\begin{tabular}{ccc}
\hline Language Features & Men & Women \\
\hline Color Terms & Associative Word & Associative Word \\
Harsh Language & Used Openly & None \\
Hedges & Avoid Quick Verdict & Expression of Uncertainty \\
Empty Adjectives & Judgmental Adjectives & Women-only Adjectives \\
Intensifiers & Negative Intensifiers & Positive Intensifiers \\
Slang & Popularly used Slang & Limited-topic Slang \\
Rapport vs Report & Report Talk & Rapport Talk \\
Opinion & Direct & Indirect \\
Quoting Someone & Relevant to Topic & Irrelevant to Topic \\
Vocabulary & Plain and Direct & Extensive Apposition \\
\hline
\end{tabular}


ENGLISH REVIEW: Journal of English Education

Volume 8, Issue 2, June 2020
p-ISSN 2301-7554, e-ISSN 2541-3643

https://journal.uniku.ac.id/index.php/ERJEE

\section{Male and female language features}

There are a total of ten language features with its own distinctive characteristics for each language feature. The language features consists of color terms, harsh language, hedges, empty adjectives, intensifiers, slang, rapport and report talk, opinion, quoting someone and vocabulary usage where each gender has their own and distinctive characteristics that are shown while the YouTube beauty influencers are presenting their video in the same topic of discussion.

The first feature, color terms, was shared by both genders. Women, however, were using associative words in describing colors. The associative words are words that are similar to the color of real objects in life such as the use of banana to describe the color yellow and lavender to describe the color light purple. In this topic of research that is related to beauty influencer, color is extremely important and crucial especially in describing the shades of product that is currently in review or tutorials. Association is one of the methods to facilitate understanding of color terms by comparing them to real objects that are generally known by the society.

On the other hand, the men in the data use a more direct approach towards color terms. Instead of using associative words towards the color terms, the men chose to explain the color instead. Thus, instead of using the word ivory, men preferred to use yellowish white. Moreover, if the men described the color with mauve instead of pinkish purple, they will be seen as either "imitating a woman sarcastically, or a homosexual, or an interior decorator" (Lakoff, 1975). Women are thought to have the ability to differentiate accurate chrome and hue than men (Perez-Calpiness, Baldovi, deFez \& Castro (1998). Consequently, different shades of the same color are more visible to women than to men.

The next language feature is harsh language. Harsh language is common in spoken communication and usually spoken by men. Harsh language contains words such as fuck which is popularly used as exclamation and bitch that is popularly used to address oneself or someone else. Women tend to avoid harsh language altogether and avoid using it in their speech. The female speakers, Nikkie and Tati, used euphemism such as dang it to replace dammit or chose the word freaking instead of fucking. Meanwhile, the male presenters Jeffree and Manny used harsh language openly in their speech. Women tend to avoid harsh languages in their speech as they were expected to act as ladies since they were a child (Lakoff, 2004).

The third feature is hedges. Hedges appear as verbs such as I wonder, I reckon, and I think as well as modal expression such as maybe, could be or the most frequently used hedge forms which is adverb such as kind of and sort of. Using hedges in communication is to lessen the impact of the statement and usually displayed as a form of politeness.

Although all presenters were using hedges in their videos, their purposes varied. Nikkie and Tati used hedges to express their uncertainty in their statements to make them appear less direct and more polite. On the other hand, Jeffree and Manny used hedges as a tool to avoid quick verdict to things that they are reviewing, avoiding immediate blame towards one product or brand. Crawford (2012) suggested that women criticized others in an acceptable way. Hence, hedge that acts as a tool to soften and lessen impact of statement is used to express their dissatisfaction and preference towards things without straightforwardly display their lack of satisfaction. On the contrary, Jeffree and Manny use hedges to show their uncertainty of the product and not to express their personal preference.

The next feature, empty adjectives, was extensively used in beauty influencers' speech. For this particular feature, Jeffree and Manny used more adjectives than Nikkie and Tati. However, the type of adjectives used by each gender differed. Female presenters were found to use women-only adjectives such as adorable, lovely, etc. and largely used by women as women often used to express their admiration towards something (Lakoff, 1975). Besides those empty adjectives, women also use the words such as vanilla and juicy as adjectives. Meanwhile, male presenters mostly used judgmental adjectives such as weird and bizarre to describe the product. Judgmental adjectives often contained a critical point of view within the expressed opinion (Mulac, Bradac \& Gibbons, 2001) as Jeffree was describing the unusual texture of the product that he is currently reviewing.

The following feature, intensifier acts as modifier to give additional emphasis and to intensify the subsequent words. Women in particular are found to frequently use intensifier in their speech. They used intensifier to show emotional emphasis and to give more impact on the effect of the message they wanted to deliver. Female presenters were found to use intensifier 
mostly to express their positive emotions such as happiness and love towards the product that they were reviewing. On the contrary, the males used intensifiers to express their opinion and judgment towards the product. Manny particularly used negative intensifier such as hella (hell of) to intensify the word that followed it. On the contrary, the females only used basic intensifiers such as really, so, too and very. Intensifiers, therefore, were used to drive the audience's emotions (Stock, 2010).

The sixth feature found is slang. Slangs can be categorized into commonly used slangs in internet-users community and limited topic slangs which exclusively belonged and used by particular group of people. Common and popular slangs consist of words commonly used nowadays for example the word tea for gossip. On the contrary, limited topic slang like cakey (to describe skin texture while wearing makeup) only belongs to the makeup and beauty community.

Thus, from the data, male presenters were found to use popular slang in their speech instead of slang that is related to beauty. The word tea and flops were found in the men's data whereas the words such as crinkly, holy grail, crunchy and cakey, which strictly related to beauty community, were found in women's speech.

Male presenters in this study were using more slangs than females. This is in accord with Poynton's (1995) indication that men generally have higher number of slangs in their speech. On the contrary, slang usage featured less in women's speech as slang is considered as informal form of communication that sometimes can be considered unfitting and raffish due to the politeness that is often applied in women's speech.

The subsequent feature is the usage of rapport talk and report talk. Rapport talk is defined as a way to communicate by establishing emotional connection to build closer relationship, thus the addressee will feel as if the speaker is talking in a more private manner even though it is a public situation by sharing their personal and private past occurrences and experiences as a way to share one's feeling (Tannen, 2013). Conversely, report talk, is a way of communication where one often share their knowledge and skills instead of personal past occurrences that seems to be intimate and private. The knowledge and skill sharing is used by the speaker to hold their position in the stage by sharing info information and output as it will assert one's position in public situation.
From the data, women were seen to use more rapport talk while men were using report talk. During the opening of the videos, women presenters began by sharing their personal information for around 30 seconds before mentioning the brands and products' name. This kind of talk was done so that the viewers can feel the intimacy and sympathy towards the speakers. In contrast, the male presenters talked less of their personal feelings and intimacy towards their viewers but merely sharing information and facts about the products.

The next feature is directness. Since the videos were about reviewing make up products, presenters should at least share their opinion or judgment on the products. Here, women generally favor uncertainty, hence strong opinion and being direct is scarce to be found. When expressing their dissatisfaction and disappointment, they stated their opinion indirectly by saying something vaguely. So, when these female presenters did not like the product, they would use body language like shaking her head along with $u h$ and $e h$, instead of saying I didn't like it. Quite the opposite, males shared their opinions directly without worrying about what other people think of them. Jeffree, for example, stated directly $100 \%$ not Jeffree Star approved when he did not like the product.

The following language feature is quoting someone else. Quotation is used when someone wants to extract word by word or phrase that someone else has said before. Quoting other people might relate with how women's personal identity is linguistically submerged where women's role in the society traditionally favor euphemism and dependent towards others instead of stand by her own opinion. Therefore, quoting other people can act as a way to give more validation towards the statement that is delivered (Crawford, 2012).

Both men and women presenters used quotation but they had different purposes. Female presenters quoted other people and themselves. The topic of the quotation was sometimes irrelevant to the topic of the video they were making. They were quoting something related to their personal life instead of beauty topic. In contrast, male presenters shared quotation of other people but the topic was still related to make up and beauty.

The last feature found in the male and female speech is apposition or the use of two or more similar words or phrases to describe one particular thing. In the data, women were found to 
use more extensive apposition when they were reviewing the products. For example, Nikkie used the words smooth, highlighted, perfected, and lifted to describe how the product works. Meanwhile, the males only used the word such as beautiful or pretty to describe similar product. Women's use of extensive apposition can be due to the fact that women often interpret accurately and sensitively towards their speech to other person especially their fellow women (Crawford, 2012; Mulac, et al., 2001).

\section{Viewers' feedbacks}

Audience's feedback towards YouTube beauty influencers can be found in each of their videos where their followers or audiences interact and give their comments as well as reactions or suggestions towards the beauty influencers.

Viewers' comments can be categorized as media discourse. Media discourse is an interaction that is happening in a digital media where the interaction is oriented to a non-present addressee where an immediate response rarely happens as it takes place digitally in the media. Comments can be given in the form of expressions or emoticons regarding the products being reviewed or the speakers themselves.

The comments for Nikkie consist of 8 positive ones and 2 negative ones. The positive commentators wrote about Nikkie's personality rather than the product she was reviewing. Meanwhile, the other two comments contain critical feedback and suggestions for her future videos as her audiences cannot see clearly regarding the texture or a closer look of the makeup on her face. Half of Nikkie's comment section also uses emoticons as a form of expression where all of the emoticons either show love sign or smiling and laughing face expression.

Next, Tati's comment section also contains 8 positive feedbacks. Similar to Nikkie's, Tati's comment section is also generally directed to her personal life instead of to the product and brands that she is reviewing. Four of the comments contain emoticon as a form of expression.

In Jeffree's comment section, all the 10 comments are positive. Most of the feedbacks found in the comment section do not feature emoticon in their comment. However, all of the comments generally said about how humble Jeffree is, knowing that he is rich but still being honest about the product when it has an expensive price tag.

The last one is Manny's comment section. Unlike the other YouTube beauty influencers,
Manny's comment section is filled with negative comments instead of positive comments especially because of his scandal of fair use of copyright content that he strike to smaller YouTube channel earlier last year. Nine out of ten comments are negative comments with emoticons of snake as one of the most used emoticons in the comment section that acts as a symbol of evil.

From the comment section, it can be seen that comments towards the beauty influencers are mostly positive. Moreover, the comments mostly applied informal language rather than formal form of communication. The connection between each YouTube beauty influencer and their audience is reflected through the comments that are given by their viewers. Nikkie, Tati and Jeffree in particular have a good relationship with their viewers whereas Manny's relationship with his viewers is considerably bad, following his scandal of copyright issue. The comment section in YouTube acts as a place to leave criticisms and suggestions as well as compliments to their favorite YouTube beauty influencers. Through this digital media, a non-verbal communication is recorded as the main mechanism of communication and participation between the beauty influencers as the sender and their audiences as the receiver.

\section{CONCLUSION}

There are two major findings that this study achieved. First, both male and female You Tube share similar language features. Those language features were color terms, harsh language, hedges, empty adjectives, intensifier, slang, rapport and report talk, direct and indirect opinion quoting other people and the use of extensive vocabulary.

However, even though some features are shared by both genders, male and female beauty influencers still showed specific characteristics in their speech. For example, the color terms expressed by females were using associative words while males used basic color terms. Also in the use of slang, female speakers limited the use of slangs to those related to makeup and beauty, while the male speakers used more general slang words.

These results indicated that male and female beauty influencers still maintain their respective gender language style although their audiences are from the opposite gender. In other words, male influencers did not accommodate their speech towards their female audiences.

Regarding the comments, most viewers gave 
positive comments towards the beauty influencers. However the comments towards the female speakers mostly relate to the speakers' personal matters; however to the males they commented on the products being reviewed.

For future research, researchers are suggested to find data from the opposite situation. For example, researchers can analyze the speech of women who are working in male dominant environment, such as women who are working in offshore oil exploration. Moreover, the data can be taken from movie or real life interaction.

\section{REFERENCES}

Bimler, D. L., Kirkland, J., \& Jameson, K. A. (2004). Quantifying variations in personal color spaces: Are these sex differences in color vision. Color Research \& Application, 29(2), 128-134. doi: 10.1002/col.10232.

Bouvier, G. (2015). What is a discourse approach to Twitter, Facebook, YouTube and other social media: Connecting with other academic fields? Journal of Multicultural Discourses, 10(2), 149162. doi: $10.1080 / 17447143.2015 .1042381$.

Broadbridge, J. (2003). An Investigation into differences between women's and men's speech. Unpublished Thesis. Birmingham: The University of Birmingham.

Coates, J. (2016). Women, men and language. New York: Routledge Linguistic Classic.

Crawford, M. (2012). Talking difference: On gender and language. Thousand Oaks, CA: Sage Publications Inc.

Eckert, P., \& McConnel-Ginet, S. (2013). Language and gender. Cambridge: Cambridge University Press.

Fatin, M. (2015). The differences between men and women language styles in writing twitter updates. Jurnal Ilmiah Mahasiswa FIB.

Gersamia, M., \& Toradze, M. (2017). Communication function of social networks in media education: The case of Georgia. The International Journal on Media Management, 3(1), 195-206.

Giles, H., \& Ogay, T. (2007). Communication accomodation theory. In B.B. Whaley \& W. Samter (Eds.), Explaining communication: Contemporary theories and exemplars (pp. 293310). Mahwah, NJ: Lawrence Erlbaum.

Gleason, J., \& Ely, R. (2002). Gender differences in language development. Biology, Society, and Behaviour: The Development of Sex Differences in Cognition, 21, 127-154.

Holmes, J. (2013). Women, men and politeness. New York: Routledge

Holmes, J. (2013b). An introduction to sociolinguistics. London: Longman.

Lakoff, R. (2004). Language and woman's place. Language in Society, 2(1), 45-80.

Leitner, G. (2017). The sociolinguistics of communication media. In F. Coulmas (Ed.), The Handbook of Sociolinguistics (pp. 129-140). Blackwell Publishing.

Mulac, A., Bradac, J. J., \& Gibbons, P. (2001). Empirical support for the gender-as-culture hypothesis: An intercultural analysis of male/female language differences. Human Communication Research, 27(1), 121-152. doi: 10.1111/j.1468-2958.2001.tb00778.x.

O'Keffee, A. (2013). Media and discourse analysis. In J. Paul Gee, \& M. Handford (Eds.), The Routledge Handbook of Discourse Analysis (pp. 441-454). Oxford: Routledge.

Perez-Carpinell, J., Baldovi, R., de Fez, M. D., \& Castro, J. (1998). Color memory matching: Time effect and other factors. Color Research \& Application, 23(4), 234-247.

Poynton, C. (1995). Language and gender: Making the difference. Oxford: Oxford University Press.

Sardabi, N., \& Afghari, A. (2015). Gender differences in the use of intensifiers. Journal of Applied Linguistics and Language Research, 2(7), 203213.

Tannen, D. (2013). You just dont understand. New York: Harper Collins.

Thomson, R., Murachver, T., \& Green, J. (2001). Where is gender in gendered language? Psychological Sciencce, 12(2), 171-175. doi: 10.1111\%2F1467-9280.00329.

Wahyuningsih, S. (2018). Men and women differences in using language: A case study of students at STAIN Kudus. Journal of English Education, Literature and Culture, 3(1), 79-90. 